\title{
HnRNP G Reduces Neuron Death in Amyotrophic Lateral Sclerosis by Preventing Abnormal TDP-43 Accumulation
}

\section{Fang Yang}

Jiangxi Provincial People's Hospital

Wenzhi Chen

Jiangxi Provincial People's Hospital

Yu Zhu

Jiangxi Provincial People's Hospital

Pei He

Jiangxi Provincial People's Hospital

Shishi Jiang

Jiangxi Provincial People's Hospital

Renshi Xu ( $\sim 13767015770 @ 163 . c o m$ )

Jiangxi Provincial People's Hospital https://orcid.org/0000-0003-0313-3434

Research article

Keywords: Amyotrophic lateral sclerosis, HnRNP G, HnRNP G-siRNA, Bax, TDP-43

Posted Date: June 16th, 2021

DOI: https://doi.org/10.21203/rs.3.rs-580041/v1

License: (1) This work is licensed under a Creative Commons Attribution 4.0 International License.

Read Full License 


\section{Abstract}

Background: Heterologous ribonucleoprotein (hnRNP) G protein was found to significantly down-regulate in the spinal cord of amyotrophic lateral sclerosis (ALS) mouse model in our previous study, but the down-regulated effects of hnRNP G in ALS haven't been known up to now. Therefore, we further studied the possible effects of hnRNP G on the spinal neuron death in TG(SOD1*G93A)1Gur (TG) mice.

Methods: Eighteen TG mice and eighteen SOD1 wild-type (WT) mice were divided into 6 groups. The hnRNP G of spinal cord were analyzed using immunofluorescent histochemistry and Western blot. Three hnRNP G-siRNA were transfected into PC12 cells and observed the alteration of proliferation rate and intracellular proteins after gene silenced using the CCK8 and Western blot.

Results: Here, we reported that the distribution of hnRNP G positive cells in the posterior horn was more than that in the central canal and its surrounding gray matter more than that in the anterior horn. hnRNP $G$ protein expressed in neurons. hnRNP G expression in the cervical and thoracic segments of TG mice in pre-onset group was significantly higher than that in control group. hnRNP G expression in the thoracic and lumbar segments of TG mice in onset group was lower than that in control group. hnRNP G expression in the cervical and thoracic segments of TG mice in progressive group decreased, while that in the lumbar segment of TG mice in progression group significantly increased. After hnRNP G-siRNA silenced, the proliferation rate of PC12 cells was slower than that in control group, SOD1 expression didn't significantly change, both TDP-43 and Bax expression significantly increased in PC12 cells after hnRNP G gene silenced.

Conclusions: Our study revealed that the distribution of hnRNP G in the spinal cord of ALS mice showed the possible protective effect on the progression of ALS, its mechanism maybe prevent neuron death through reducing abnormal TDP-43 accumulation in the spinal cord of ALS-like mice.

\section{Background}

Amyotrophic lateral sclerosis (ALS) is the commonest motor neuron disease (MND), which is characterized by the damage of both upper and lower motor neurons, manifested as the progressive weakness, muscular atrophy and fascicular fibrillation of muscle as well as pyramidal tract signs. Most patients died of respiratory paralysis within 3-5 years [1]. Current clinical used drugs only could partly postpone the disease progression of ALS, their effect mechanisms include the elimination of oxygen free radicals and the protection of neurons. Up to now, there haven't been any reliable specific drugs curing ALS. Several studies have found that the pathogenesis of ALS is closely related to genetic factors, the toxicity of excitatory amino acid, the damage of oxidative stress, the damage of axonal transport, the defect of mitochondrial function, and the abnormal aggregation of protein so on. Their effects can exert synergistic effects each other [2]. Recently found pathogenic mechanisms of ALS include RNA metabolic dysfunction, the defects of cytoplasmic transport, and the dynamics damage of RNA particles and other 
ribonucleoprotein body [1]. These pathogenic factors can lead to the disorder of gene transcription, splicing, translation and other related processes, and further damage cells and /or tissues.

The pathological feature of ALS is the generation of cytoplasmic inclusion bodies, aggregating in damaged motor neurons and oligodendrocytes. Inclusion bodies not only exist in spinal cord, but also exist in multiple brain regions, such as frontal cortex, temporal cortex, hippocampus and cerebellum $[3,4]$. The aggregation of abnormal proteins and the generation of inclusion bodies have been considered as the pathological characteristics of several neurodegenerative diseases including ALS. Among them, the aggregation of abnormal proteins and the generation of inclusion bodies are the commonest in spinal motor neurons. Ubiquitin positive inclusion body is a sign of ALS pathology. In ALS, some proteins encoded by mutant genes, such as SOD1, TDP-43, FUS, OPTN, UbqIn2 and NEFH, are the important components of inclusion bodies [5-7].

In 1993, the first mutant SOD1 gene [8] was found in the patient of familial ALS (fALS). From then on, more than 50 potential pathogenic genes of ALS have been found up to now, among them, including c9orf72, TDP-43, FUS, heterologous ribonucleoprotein (hnRNP) A1, Sqstm1, VCP, OPTN, Pfn1 [9]. These genes are roughly divided into the following categories: The genes affected the control of protein stability and expression quality, the genes affected the normal function and metabolism of RNA, and the genes interfered with the cytoskeleton dynamics of distal axons of motor neurons. The advances in studied technologies have prompted researchers to sequence a wide range of DNA in patients with sporadic ALS (sALS), and found that the genetic variation of ALS gene isn't uncommon. 1-3\% of sALS patients are caused by the missense mutations in SOD1 gene [10], and 5\% or more SALS are caused by the abnormal amplification of introns in c9orf72 gene [11].

In 2006, Lee et al. found that RNA binding protein (RBP) TDP-43 deposited in brain and spinal cord of ALS patient, and aggregated in cytoplasm. TDP-43 mislocation is now widely recognized as the characteristic of partial SALS and fALS [12]. Subsequently, the mutations of other ALS related proteins including FUS and hnRNP A1 were identified. These proteins were mutated after bound with RNA, which made RNA biological role be more concerned in the pathogenesis of ALS. Because the mutations of RNA binding proteins (RBPs) gene are found in neurodegenerative diseases, the dysfunction of RBPs is clearly evolving into the central theme of neurodegenerative diseases, and the dysfunction of RNA processing and the phagocytosis of aggregation protein become an important mechanism related to ALS [13]. The RBPs closely related to ALS include TDP-43, FUS, c9orf72, hnRNP A1, hnRNP A2/B1, Matr3, SETX, ELP3, atxn2, ANG, SMN1 and SMN2 $[14,15]$. In addition, many other RBPs have been found to show changes in subcellular distribution in the neurons and/or glial cells of ALS patients, but the mutations caused ALS have not been known [16], which indicates that even if the gene of RBPs does not mutate, it can also cause the destruction of RNA stability in ALS, or affect the metabolism and stability of RNA during the occurrence and development of ALS. Only $4 \%$ of fALS patients show the gene mutation of TDP-43, about $97 \%$ of ALS patients had dis-localization and the inclusion body of TDP-43 protein. It suggests that even if there is no relevant mutation, the cytoplasmic and intranuclear inclusion bodies are common in ALS patients [17]. 
Both TDP-43 and FUS are involved in RNA related pathways, they play some roles at many steps of RNA regulation, including RNA transcription, splicing, transportation, translation and microRNA production [18]. Both TDP-43 and FUS proteins interact directly with polyphase ribonucleoprotein complexes, regulate RNA splicing and transport, both TDP-43 and FUS have the similar biological roles in RNA related pathways [19]. The cellular cytotoxicity of mutants and/or cytoplasmic dislocated TDP-43 and FUS might be caused by the following reasons: (1) the loss of normal nuclear function leads to the disorder of nuclear RNA processing; (2) obtains the additional cytoplasmic RNA binding activity; (3) the polymerization dependent toxicity [7, 20-22]. More and more evidences show that the neurotoxicity generates through various cellular pathways, such as the RNA mismatch and the transcription reduction of c9orf72 gene, the disorder of transport between nuclear and cytoplasm, the stress of nuclear protein and DNA damage [23-27]. The break of DNA strand is the most serious types of DNA damage. If the broken DNA are not repaired properly, which usually lead to cell death. The hnRNP A1 is a member of hnRNP family, involves in a variety of RNA metabolism [28]. Several studies find that the hnRNP A1 negatively regulates its mRNA expression by inhibiting the intron 10 splicing of hnRNP A1 pre-mRNA in cell models. This mechanism might be the self-regulation of hnRNP A1 expression, and the low-level hnRNP A1 overexpression can cause cytotoxicity by activating the pathway of mitochondrial apoptosis $[29,30]$. It is suggested that the level of hnRNP A 1 is strictly controlled within a certain range by the selfregulation of mRNA, so that no cytotoxicity of hnRNP A1 expression occurs at the physiological condition.

Among recent discovered RBPs, hnRNP $\mathrm{G}$ is the most prominent in the familial members of more than 20 RBPs proteins. TDP-43, FUS and hnRNP A1 are members of hnRNP protein family that regulate RNA metabolism at each stage of RNA life cycle [31-33]. hnRNPs help to control the maturation of newly formed hnRNA and pre-mRNA, stabilize mRNA and control its translation during cell transport. hnRNPs are key proteins in cellular nucleic acid metabolism [34]. Since neurons are the permanent cells, the steady state of mRNA needs to be strictly regulated, and the steady state of mRNA is very vulnerable to the dysfunction of RBPs including hnRNPs [35].

hnRNP $\mathrm{G}$ is the product of RNA binding motif protein and RNA binding motif protein X-linked (RBMX) gene, is the only glycosylated hnRNP that can directly bind to RNA. The RNA binding motif protein Ylinked gene is located on $\mathrm{Y}$ chromosome, is formed by the reverse transposition of RBMX [36-38]. hnRNP $G$ can be used as a pre-splicing factor of $m R N A$, involves in the selection of specific splicing sites, is related to the post transcriptional new mRNA of RNA polymerase II, and regulates the selection of premRNA alternative splicing sites [39]. Recent studies have shown that hnRNP $G$ is an active regulator of splicing mechanism in neurodegenerative diseases. Firstly, hnRNP G promotes the expression of exon 7 of survival motor neuron. The homozygous deletion of hnRNP G gene leads to the common motor neuron disease called the spinal muscular atrophy [40]. Secondly, the microtubule associated protein like Tau is regulated by the interaction of cis- and trans- factors including hnRNP G. In human genes, the exon 10 of Tau is a binding domain of selective splicing, the wrong splicing of Tau gene results in the frontotemporal dementia of Parkinson's syndrome [41]. It is obvious that hnRNP $G$ has various and complex functions. Our studied groups found that the hnRNP G protein in the spinal cord of TG(SOD1*G93A) 1 Gur (TG) mice 
was significantly reduced through the methods of proteomic analysis [27]. The purpose of this study is to further explore the possible roles and mechanisms of hnRNP G in the pathogenesis of ALS.

\section{Methods}

\section{Cell line and animal}

The PC12 cell line (Cell Storage Center of Wuhan University) used in experiment derives from the pheochromocytoma of rats. The culture conditions of PC12 cells were as follows: The constant temperature of $37^{\circ} \mathrm{C}, 5 \%$ of carbon dioxide and low sugar DMEM medium. TG mice and wild-type (WT) mice were provided by the Model Animal Research Institute of Nanjing University. All studies and experiments of animal included the rationale of testing animals were conducted in accordance with the Guide for the Care and Use of Laboratory Animals of China, and protocols were reviewed and approved by the Animal Care and Use ethics Committee (ACUC Number 2019-11-02) of Jiangxi Provincial People's Hospital, First Affiliated Hospital of Nanchang Medical College, Affiliated People's Hospital of Nanchang University, China.

\section{Extraction of mouse DNA}

Approximate $0.3 \mathrm{~cm}$ mouse tails were taken into EP tube, added $75 \mathrm{ul} 50 \mathrm{mM} \mathrm{NaOH}$. Mixed solution was put in water bath at $97^{\circ} \mathrm{C}$ for $30 \mathrm{~min}$. Added $7.5 \mu \mathrm{l} 1 \mathrm{M}$ Tris $\mathrm{HCl}$ into specimen, centrifuged by $4,000 \mathrm{~g}$ for 1 min. Supernatant was the extracted DNA.

\section{PCR amplification}

The primers (Shanghai biotechnology company) of PCR were as follows: The upstream primer of mouseG93A*SOD1: 5'-cat cag cct act ccc tga-3', downstream primer: 5'-cgc gac taa caa tca atc aaa gtg a-3'. The upstream primer of mouse-IL-2: 5'-cta ggc aca gaa ttg aaa gat ct-3', downstream primer: 5'-gta ggt gga aaa ttc tag cat cat cc-3'. The PCR reaction condition of extracted mice DNA was as follows: $25 \mu$ reaction

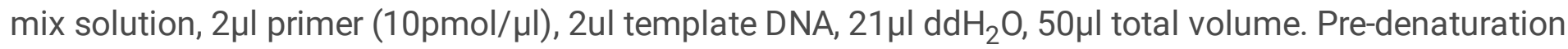
at $95^{\circ} \mathrm{C}$ for 5 min once, 35 reaction cycles of denaturation at $94^{\circ} \mathrm{C}$ for $30 \mathrm{sec}$, annealing $60^{\circ} \mathrm{C}$ for $1 \mathrm{~min}$, and extend at $72^{\circ} \mathrm{C}$ for $1 \mathrm{~min}$, final extension at $72^{\circ} \mathrm{C}$ for 2 min once, hold at $16^{\circ} \mathrm{C}$. Detected PCR results by the electrophoresis of agarose gel. The G93A*SOD1 positive mice were used in experimental groups, the G93A*SOD1 negative mice (WT) were used in control groups.

\section{Animal experiment group}

Eighteen TG mice were randomly selected as experimental groups and 18 WT mice were randomly used as control groups. We designed a randomization of animals to experimental groups. After the genotype identification of mice, TG and WT mice were randomly selected for study. Firstly, we marked a code for each mouse. The samples of mice were then blindly stained and observed, the staining and observing researcher didn't knowing the identity of sample. Finally, we matched the results of each sample to its true identity and summarize for analysis. 
Experimental groups and control groups were divided into three subgroups by using random number labeled method. The mice bred to $60-70$ days were used as pre-onset groups, that bred to $90-100$ days were used as onset groups, that bred to 120-130 days were used as progression groups. Each subgroup consisted of six mice. Each subgroup was randomly divided into immunofluorescence stained groups and Western blot groups. After animal was anesthetized, the samples of spinal cord were dissected at $4^{\circ} \mathrm{C}$. If the mice died unexpectedly during the raise or the operation of specimen preparation was failed, the experimental mice can be supplemented randomly.

\section{Treatment of animal experimental materials}

When mice grew to experimental asked days, the spinal cord was dissected. The procedures of spinal cord dissection were as follows: Mice were anesthetized intraperitoneally by injected $0.1-0.2 \mathrm{ml}$ of $10 \%$ chloral hydrate based on counting of body weight/each kilogram. Firstly, approximate $20 \mathrm{ml}$ pre-cooled $0.9 \%$ sodium chloride injection was perfused. If specimens were used as the analysis of Western blot, spinal cord was taken out immediately at $4^{\circ} \mathrm{C}$. If specimens were used in immunofluorescence stain, then continued to slowly infuse approximate $20 \mathrm{ml} 4 \%$ paraformaldehyde. Entire spinal cord was immersed in $4 \%$ paraformaldehyde at $4{ }^{\circ} \mathrm{C}$ overnight. After paraformaldehyde fixation, spinal cord was conducted gradient dehydration in the alcohol of different concentrates, then immersed in sucrose solution and placed in $4^{\circ} \mathrm{C}$ refrigerator overnight. The dehydrated spinal cord was divided into cervical, thoracic and lumbar segments, were embedded with OCT solution (Sakura Fineteak Japan Co. Ltd).

\section{Immunofluorescence stain of mouse spinal cord}

The spinal cord of each mouse was cut into $12 \mu$ l thick sections by the technique of constant temperature frozen section. Anti hnRNP G antibody and anti NeuN antibody were used in experimental groups and control groups. The NeuN positive cells showed green fluorescence, the hnRNP G positive cells showed red fluorescence. Staining steps are as follows: added $0.3 \%$ Triton X-100 for 10 min, washed with $0.01 \mathrm{M}$ PBS for 3 times of $5 \mathrm{~min}$. The tissue sections were sealed with $5 \%$ BSA for $1 \mathrm{~h}$, then incubated by primary antibody in accordance with following concentrate: Rabbit anti hnRNP G antibody: 1:200 (ab190352, Abcam Co. Ltd), mouse anti NeuN antibody: 1:400 (ab104224, Abcam Co. Ltd). The tissue sections with primary antibody were kept in a dark box overnight at $4^{\circ} \mathrm{C}$. Next day, slice was washed with $0.2 \%$ Tween20 for 5 times of 5 min. Then slices were incubated by secondary antibody in dark RT for $2 \mathrm{~h}$, after incubated by secondary antibody, slice was washed 5 times with $0.2 \%$ Tween-20 for 5 min each time. The concentrate of secondary antibodies was goat anti mouse IgG (FITC) 1:200 (ab150113, Abcam Co. Ltd), donkey anti rabbit IgG (TRITC) 1:250 (ab150075, Abcam Co. Ltd). Slice was washed 3 times with 0.01M PBS for 5 min each time, sealed it with the anti-fluorescence quenching sealing solution. Used the fluorescence microscope with camera to observe and took the pictures of all parts.

\section{PC12 cells transfection of hnRNP G siRNA}

In order to finding the appropriate transfection concentration, the concentration gradient was screened in the pre-experiment. The transfection experiment was divided into following five groups: blank control group adding normal culture medium, negative control group adding negative control transfection 
complex, hnRNP G siRNA 1 transfection group adding sequence 1 transfection complex of hnRNP G, hnRNP G siRNA 2 transfection group adding sequence 2 transfection complex of hnRNP G, hnRNP G siRNA 3 transfection group adding sequence 3 transfection complex of hnRNP G. The sequences of siRNAs (Shanghai GenePharma Co. Ltd) were shown in the following: The forward and reverse primers of hnRNP G siRNA1 sequence were GCU CUU UAU UGG UGG GCU UTT and AAG CCC ACC AAU AAA GAG CTT, that of siRNA2 were CCC GAG AGA UGA UGG AUA UTT and AUA UCC AUC AUC UCU CGG GTT, that of siRNA3 were GCG UGA CUA UUC GGA UCA UTT and AUG AUC CGA AUA GUC ACG CTT. The results of transfection gradient experiment were in Additional file 1: Table S1-2.

The $1-1.5 \times 10^{5}$ cells were added into each pore with $1,000 \mu$ l growth medium for $18-24 \mathrm{~h}$ before transfection experiment. Lip2000 transfection reagent (YG0398, Shanghai Kemin Biotechnology Co. Ltd) was mixed gently in RT before used. 95ul DMEM was added into sterile EP tube, $3 \mu l$ hnRNP G siRNA $(20 \mu \mathrm{M})$ was added into the EP tube containing DMEM culture medium, and mixed well. Then, $2 \mu \mathrm{l}$ lip2000 transfection reagent was added into EP tube and mixed well at RT for $20 \mathrm{~min}$. The processes of transfection were as following: Firstly, $900 \mu$ fresh DMEM medium were added into each plate of 12 wells. $100 \mu \mathrm{l}$ transfection mixtures were added into each pore, the final volume was $1,000 \mu \mathrm{l}$. Shook pore plate gently and cultured cells in $5 \% \mathrm{CO}_{2}$ incubator at $37^{\circ} \mathrm{C}$. Total RNA can be extracted after the culture of $24-$ $96 \mathrm{~h}$.

\section{Detection of gene silencing efficiency by real-time fluorescence quantitative PCR}

\section{RNA extraction from PC12 cells transfected with hnRNP G siRNA and reverse transcription PCR}

A proper amount of Trizol was added into PC12 cells, placed the split cells in a ribozyme free EP tube. Added $1 / 5$ Trizol of chloroform. Centrifuged by $12,000 \mathrm{~g}$ at $4^{\circ} \mathrm{C}$ for $20 \mathrm{~min}$, put the supernatant into another EP tube with the equal volume of isopropanol. Centrifuged by $12,000 \mathrm{~g}$ at $4^{\circ} \mathrm{C}$ for $15 \mathrm{~min}$, and discarded the supernatant. A proper amount of anhydrous ethanol was added. Centrifuged by $12,000 \mathrm{~g}$ at $4^{\circ} \mathrm{C}$ for $10 \mathrm{~min}$, and discarded the supernatant. DEPC (Diethyl pyrocarbonate) water was added into the dissolve RNA pellet. The concentration of RNA samples was measured by a spectrophotometer. The extracted RNA was used for reverse transcription PCR (RT-PCR). The experimental steps were as follows: $2 \mu \mathrm{l} 5 x$ primescript $^{\mathrm{TM}}$ reverse transcription Master Mix, $2 \mu$ l total RNA, and added RNase free $\mathrm{ddH}_{2} \mathrm{O}$ to $10 \mu$ l. The reverse transcription procedure was as follows: Reverse transcription reaction at $37^{\circ} \mathrm{C}$ for $15 \mathrm{~min}$, the inactivation reaction of reverse recording enzyme at $85^{\circ} \mathrm{C}$ for $5 \mathrm{sec}$.

\section{Detection of hnRNP $\mathrm{G}$ expression in each group by real-time fluorescence quantitative PCR}

The steps of real-time fluorescence quantitative PCR (QRT PCR) were as follows: The primers of hnRNP G and internal reference $\beta$-actin were as follows: the upstream primer of hnRNP $G$ was 5 -aaa ctt tgg acc 
aca cat atc c-3', the downstream primers was 5'-aag cca cgc tta cac ata cta-3', the upstream primer of $\beta$ actin was 5 '-ccg tga aaa gat gcc cag at-3', the downstream primers was 5'-GGA CAG TGA GGC CAG GAT AGA-3', Prepared the QRT PCR reaction solution on ice according to the following components: $10 \mu \mathrm{I}$ TB

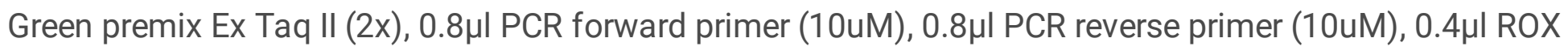
reference dye or dye II (50x), $2 \mu \mathrm{l} 1 \mathrm{x}$ reverse transcription reaction solution (CDNA solution from RT-PCR), $6 \mu \mathrm{l}$ sterile water. Used the stepone plus real time PCR system to conduct QRT PCR reaction, standard PCR amplification procedures were as follows: Stage 1: pre-denaturation of $95^{\circ} \mathrm{C}$ for 30 sec once, stage 2: PCR reaction of $95^{\circ} \mathrm{C}$ for $5 \mathrm{sec}, 60^{\circ} \mathrm{C}$ for $30 \mathrm{sec}$ and total repeated 40 times. After amplification, observed the amplification curve and fusion curve of QRT PCR, obtained the effective CT value and analyzed using Graphpad Prism software.

\section{CCK8 detection of cell growth curve after gene silenced}

The growth curve of PC12 cells under the normal condition and after the gene silenced was detected by the CCK8 kit. The steps were as follows: added PC12 cell suspension of $100 \mu \mathrm{l} /$ each well into 96 wells plate, and placed it in an incubator for $24 \mathrm{~h}$. The transfection reagent was added to the pored plate and placed in incubator for further incubation for $24-48 \mathrm{~h}$. The tranfected PC12 cells were changed the new culture medium and added $10 \mu \mathrm{l} \mathrm{CCK8}$ solution into each pore. After the culture dish was placed in the incubator for $1 \mathrm{~h}$, the absorbance of each pore at 450nM was measured by enzyme analyzer. Data analysis was used by Graphpad Prism software.

\section{Western blot}

The operation steps of spinal protein extraction and quantification were as follows: Mouse spinal cord was ground by a glass homogenizer, added a proper amount of tissue Ripa lysis solution containing $1 \mathrm{mM}$ PMSF. Lysis liquid was centrifuged by $13,000 \mathrm{~g}$ at $4^{\circ} \mathrm{C}$ for $15 \mathrm{~min}$, supernatant was extracted proteins. The extracted proteins were quantified according to instructions of BCA kit (Solarbio Co. Ltd, Beijing, China).

The protein extraction and quantification procedures of PC12 cells after hnRNP G silenced are as follows: Took $1 \mathrm{ml}$ of Ripa solution into the solution of PC12 cell, added 10 1 l PMSF solution, washed 3 times with PBS, added $100-150 \mu$ lysate solution into each cell of twelve pore plates, centrifuged by $10,000-$ $14,000 \mathrm{~g}$ at $4^{\circ} \mathrm{C}$ for $3-5 \mathrm{~min}$, supernatant was extracted proteins. The quantification of protein concentration was detected by BCA kit.

Western blot was used for the semi-quantitative analysis of spinal proteins in each group. Protein samples $(20-50 \mu \mathrm{g})$ were conducted electrophoresis by SDS-PAGE gel, the electrophoresis of $100 \mathrm{~mA}$ current and $80 \mathrm{~V}$ voltage was performed for $30 \mathrm{~min}$, then voltage was changed to $120 \mathrm{~V}$ electrophoresis. Conducted the membrane transfer of protein at $200 \mathrm{~mA}$ and $100 \mathrm{~V}$ for 30-60 min. Sealed the PVDF membrane using $5 \%$ skimmed milk solution for $1-2 \mathrm{~h}$ at RT, took out PVDF membrane and washed with $1 \mathrm{x}$ TBST 3 times for 10 min each time. Put PVDF membrane into the solution of corresponding primary antibody and incubated at $4{ }^{\circ} \mathrm{C}$ overnight, washed the membrane with $1 \times$ TBST 3 times for 10 min each time. Put PVDF membrane into secondary antibody to incubate at RT for $1-2 \mathrm{~h}$, and washed membrane 3 
times for 10 min each time. Added mixed luminescent liquid for $30 \mathrm{sec}-2 \mathrm{~min}$, and put it in the dark box for exposure, used Image $J$ software to analyze protein band density. The concentrations of primary antibody were as follows: a-Tubulin 1:1,000 (Cat.No.66031-1-lg, Proteintech Co. Ltd), hnRNP G 1:1,000 (ab190352, Abcam Co. Ltd), SOD1 1:1,000 (Cat.No.67480-1-lg, Proteintech Co. Ltd), Bax 1:1,000 (Cat.No.60267-1-Ig, Proteintech Co. Ltd), TDP-43 1:1,000 (Cat.No.66734-1-Ig, Proteintech Co. Ltd) and $\beta$ Actin 1:2,000 (Cat.No.66009-1-Ig, Proteintech Co. Ltd). The horseradish peroxidase (HRP)-secondary antibody 1:1,500-2,500 (ab181658, Abcam Co. Ltd) was selected according to corresponding samples and primary antibodies.

To verify the specificity of primary antibodies, negative controls included fluorescent immunohistochemical staining and Western blot that were incubated in the absence of primary antibody or in a presence of nonimmune normal serum in the same dilution as the primary antibody, as well as antigen-antibody pre-absorption experiments with the native antigen at $4^{\circ} \mathrm{C}$ for $24 \mathrm{~h}$, and other procedures are same in the same sample.

\section{Statistical analysis}

The Image $J$ software was used to count the hnRNP G positive cell number of immunofluorescence image and measure the gray value of Western blot image, and the Photoshop was used to adjust the images. Total amount of hnRNP G positive cells in each distinct anatomic regions of spinal cord was counted at 200 magnifications in 10 sections, the hnRNP G positive cells sum of all 10 sections was divided by the section number, 5 mice per group were used, the averaged amount of hnRNP G positive cells was used for the quantitative analysis. All data were analyzed with the IBM SPSS Statistics 25 , the normality and variance homogeneity was assessed, For unpaired samples, student's t-test was used if it obeys normal distribution and variance was homogeneous; Welch's t-test was used if normal distribution was obeyed but variance was not uniform; Mann-Whitney $U$ test was used if normal distribution was not obeyed. $\mathrm{P}<0.05$ showed the statistical difference.

\section{Results}

\section{Distribution of hnRNP G positive cells in mouse spinal cord}

It was found that the hnRNP G positive cells were widely distributed in the anterior horn, the central canal, the posterior horn and other parts of spinal cord, and there were the significant differences in the distribution of hnRNP G positive cells in the different segments of spinal cord and in the different regions of the same segments. The distribution of hnRNP G positive cells in the different regions of same spinal cord in the cervical, thoracic and lumbar segments showed a pattern of posterior horn more than the central canal and its peripheral gray matter more than the anterior horn. The results showed that the number of hnRNP $G$ positive cells distributed in the anterior horn of spinal cord at the pre-onset stage of TG group (Mice age of 60-70 days) was significantly higher than that of WT group ( $P<0.0001$, Fig. 1 , the detail data seen Additional file 2: Table S1-3). The distribution of hnRNP G positive cells in the central canal and its surrounding gray matter of lumbar spinal cord in the TG mice of pre-onset group was also 
significantly higher than that of WT mice $(\mathrm{P}<0.0001$, Fig. 2, the detail data seen Additional file 3: Table S1-3). The distribution of hnRNP G positive cells in the posterior horn of thoracic spinal cord in the TG mice of the pre-onset group was significantly lower than that of WT mice $(P<0.01$, Fig. 3 , the detail data seen Additional file 4: Table S1-3). The number of hnRNP G positive cells in the spinal anterior horn of TG mice (90-100 days) in the onset group was significantly lower than that of WT mice $(P<0.001$, Fig. 1 , the detail data seen Additional file 2: Table S1-3). The number of hnRNP G positive cells in the central canal and its surrounding gray matter of each spinal segment in the TG mice of onset group was significantly reduced compared with that in the WT mice $(P<0.01$, Fig. 2, the detail data seen Additional file 3: Table S1-3). The number of hnRNP G positive cells in the posterior horn of spinal cervical and lumbar segments at the progressive group of TG mice (120-130 days) was significantly lower than that of WT mice ( $\mathrm{P}=$ 0.037, Fig. 3, the detail data seen Additional file 4: Table S1-3). The number of hnRNP G positive cells in the spinal central canal and its surrounding gray matter of TG mice at the progressive group was also decreased compared with that of WT mice $(P<0.01$, Fig. 2, the detail data seen Additional file 3: Table S1$3)$.

\section{The double immunocytochemistry in mouse spinal cord}

In this study, both hnRNP G antibody and the NeuN antibody of neuron biomarker were used to doubly label in the spinal different segments of TG mice in the onset group (Fig. 4). It was observed that there was the immunologic co-localization of hnRNP G positive cells and neurons in the different spinal segments at the onset stage. Moreover, the hnRNP G positive cells were mainly distributed in the central canal.

\section{Western blot of mouse spinal cord}

Western blot was used to analyze the expression of hnRNP G protein in the spinal cord at the different periods and stages of WT and TG mice (Fig. 5, the detail data seen Additional file 5: Table S1-3). The results showed that the hnRNP G protein of TG mice in the cervical segment was significantly higher than that of WT mice in the pre-onset group $(P<0.01)$, and the hnRNP $G$ protein of TG mice was significantly lower than that of WT mice in the progression group $(P=0.16)$ (Fig. $5 \mathrm{~A}$, the detail data seen Additional file 5: Table S). The hnRNP G protein of TG mice in the thoracic segment was significantly higher than that of WT mice in the pre-onset group $(P=0.01)$, the hnRNP $G$ protein of TG mice was significantly lower than that of WT mice in the onset group $(P=0.03)$, and the hnRNP G protein of TG mice was significantly higher than that of WT mice in the progression group $(P<0.01)$ (Fig. 5B, the detail data seen Additional file 5: Table S2). The protein of hnRNP G decreased significantly in the progression TG mice compared with WT mice $(P<0.0001)$ (Fig. 5C, the detail data seen Additional file 5: Table S3).

\section{Detection of silencing efficiency of hnRNP G-siRNA gene in PC12 cells}


The mRNA level of hnRNP G gene detected by the real-time fluorescent quantitative PCR was significantly lower than that of control groups including both blank and negative control groups (Fig. 6A, the detail data seen Additional file 6: Table S1). The quantitative analysis of hnRNP G protein in cells by Western blot showed that the content of hnRNP G protein in the hnRNP G gene silenced group was significantly lower than that in the control groups including both blank and negative control groups $(P<0.001)$ (Fig. 6B, C, the detail data seen Additional file 6: Table S2).

\section{Effect of hnRNP G gene silenced on PC12 cells}

In this experiment, the CCK8 method was used to draw the growth curve of PC12 cells without any treatment (Fig. 7A), and it was observed that the cell survival rate of PC12 cells decreased after interfered by the hnRNP G-siRNA ( $P<0.01$, Fig. 7B, the detail data seen Additional file 7: Table S1-3).

\section{Expression of TDP-43/Bax/SOD1 in PC12 cells after hnRNP G gene silenced}

Western blot was used to detect the expression of TDP-43, SOD1 and Bax (Fig. 7C-F, the detail data seen Additional file 7D: Table S4-5, Additional file 7E: Table S6-7 and Additional file 7F: Table S8-9). It was found that the expression of SOD1 protein was not significantly changed in the PC12 cells after the interference of hnRNP G-siRNA, the expression of Bax protein involved in the apoptosis was significantly increased, and the expression of TDP-43 protein was also significantly increased $(P<0.01)$, which suggested that hnRNP $G$ might be related to apoptosis and the abnormal accumulation of TDP-43 protein.

\section{Discussion}

Our study further studied the distribution and expression alteration of hnRNP G protein in the spinal cord of SOD1*G93A transgenic ALS model mice and the possible mechanism of hnRNP $G$ in the pathogenesis of ALS on the base of our previous study. The results showed that hnRNP $G$ were widely distributed in the anterior horn, the central canal and its around grey, the posterior horn and other regions of spinal cord, and there were significant differences in the distribution of hnRNP G in different segments of spinal cord and in the different regions of same segment. The expression of hnRNP G protein in the spinal cord of TG mice significantly increased at the pre-onset stage, but the expression of hnRNP G protein in the spinal cord of TG mice decreased at the onset stage, and also decreased compared with the progression TG mice. It is suggested that the hnRNP G protein plays the certain effects in the pathogenesis of ALS model mice, which is that the decrease of hnRNP G protein expression may promote the development of ALS in mice. In order to further understand the effect of hnRNP G in neuronal damage or apoptosis, we conducted the hnRNP G-siRNA interference in the PC12 cells by silenced the partial hnRNP G gene. The experimental results showed that after reducing the expression of hnRNP G in PC12 cells, there was no significant change in the expression of SOD1, but the expression of TDP-43 and Bax significantly increased, and the cell survival rate significantly decreased. These results indicated that hnRNP G was 
very important for the normal expression of TDP-43 and Bax. Because the abnormal expression of TDP43 can lead to the abnormal distribution and aggregation of hnRNP G, ultimately cause the damage and death of neurons and promote the occurrence and development of ALS $[6,12,19,22]$. The hnRNP G protein might play a positive role in the occurrence and development of ALS by regulating the TDP-43 expression and controlling apoptosis, because the Bax protein accelerated the neuron apoptosis [42] significantly increased and the cell death significantly increase on the inhibition of hnRNP G. Our result found that hnRNP G extensively distributed in neurons. Therefore, we suggested that hnRNP G was closely associated with the death of neurons, because the more cells damaged in ALS were neurons [1, 3].

\section{Effect of hnRNP G on neurons damage and/or apoptosis in ALS}

It has been found that the expression of hnRNP G increased at the early stage of neuron damage, and gradually decreased to the normal level after reaching the peak value, and the immunofluorescence stain found that there was co-localization between hnRNP $G$ and neuron and the activated caspase-3 [43]. The neuron apoptosis is an important part of neuron damage. Caspase-3 is an important regulator of neuronal apoptosis, which has been proved to play a key role in the pathological neuron death of nervous system. In the adult mice with the acute spinal cord injury, the expression of hnRNP G peaked on the first day after injury, and then returned to the basic level on the 14th day [44]. Moreover, the hnRNP $G$ is also involved in the brain formation of zebrafish. If the hnRNP G gene is knocked down, zebrafish has the characteristic brain morphological defects, such as the enlarged tectum and ventricles. In the zebrafish of knockdown hnRNP G gene, the abnormal development of nerve, muscle and spinal cord was also detected [45]. The role of hnRNP G in the brain development of zebrafish suggests that the human hnRNP $\mathrm{G}$ gene may be involved in the functional and behavioral defects caused nervous system diseases [46].

In this study, we found that the hnRNP G protein in the spinal cord of TG mice increased at the pre-onset stage, but significantly decreased at the onset stage, and increased at the progression stage relative to the onset stage, which was the same with the past reported results of increased expression and then decreased expression in neurons after the injury of spinal cord [44]. Our results showed that the expression of hnRNP G significantly increased at the pre-onset stage of TG mice due to the aggregation of SOD1 protein, which resulted in the neuron damage and/or apoptosis. As for the increase of hnRNP G in the spinal cord of progression TG mice, it might be due to the reason that hnRNP G, like other hnRNPs, could negatively regulate itself by closely binding with its own RNA in the nucleus [30].

The double labeling stain of immunofluorescence showed that biomarkers of neurons and astrocytes had doubly labeled with the hnRNP G immunoreactivity, while microglia had no double label with hnRNP G immunoreactivity. The expression of hnRNP $G$ was mainly increased in neurons and astrocytes. In addition, the hnRNP G proliferating cellular nuclear antigen and the hnRNP G activated caspase-3 were detected in astrocytes and neurons respectively [44]. The expression of Bcl-2, Bax and the activated caspase- 3 in mice with acute spinal cord injury is also changed, which will lead to the secondary tissue injury, the regeneration damage and the cell dysfunction $[47,48]$. In our study, only doubly labeled hnRNP 
$\mathrm{G}$ and the neuron marker NeuN were found to have immune-co-localization. Therefore, the decrease of hnRNP G expression may be related to the death of spinal neurons in TG mice.

\section{Effect of hnRNP G on TDP-43 in ALS}

Although the role of TDP-43 in the RNA metabolism has been basically clear, there are still some problems to need be deeply comprehended, for example, does the change of RNA function play a role in diseases? Do hnRNPs related to ALS play a sole independent or synergistic role? Like many other hnRNPs, the functions of TDP-43 and hnRNP A1 may be the extremely dose sensitive, so they can be selfregulated by closely binding with their own RNA in the nucleus [30,49]. When the cytoplasmic aggregates deplete TDP-43 in the nucleus, the level of TDP-43 is up-regulated due to the lack of self-regulation [50], which results in a vicious cycle of TDP-43 RNA expression increase and cytoplasmic aggregation. Deshaies et al. reported that the loss of TDP-43 function resulted in the hnRNP A1 protein increase in the cytoplasm, and the level of hnRNP A1 protein decreased in the ALS patient's neuronal nucleus [51]. The activation of RBPs compensation in the ALS patients with the TDP-43 gene mutation leads to the increase of splicing repressor expression in order to offsetting the loss of TDP-43 function. It was found that the overexpression of hnRNP $u$ and hnRNP A1/A2 can inhibited the TDP-43-induced neuronal cell death in mice [52].

The expression of hnRNP G significantly increased at the pre-onset stage of TG mice, then decreased to the basic level at the progression stage of TG mice, which may be due to the fact that hnRNP G, like other hnRNP, can regulate itself negatively by closely binding with its own RNA in the nucleus, but this needs to be further proved. There was co-localization of hnRNP G positive cells and neurons in the different segments of mice spinal cord at the different stages, the decrease of hnRNP G expression might be related to the neuron death in the spinal cord of TG mice. After PC12 cells were interfered by hnRNP GsiRNA, the proliferation activity of PC12 cells was lower than that of the control groups including both blank and negative control groups, and the expression of TDP-43 and Bax protein in PC12 cells significantly increased as well as the expression of hnRNP G significantly decreased, which might further lead to the abnormal aggregation of TDP-43 and the apoptosis of neurons in ALS.

In this study, we only observed the immune-co-localization of NeuN labeled neurons and hnRNP G, and did not doubly label other neural cells with the immunofluorescence stain. Relationships between hnRNP $G$ protein and astrocytes, microglia, oligodendrocytes and undifferentiated neurons were not observed. If that, it would further clarify the target cells of hnRNP G protein. Moreover, this study did not up-regulate the expression of hnRNP G protein and did not observed the expression of related proteins in cells after the up-regulation, did not clarify the mechanism and effect of abnormal accumulation of TDP-43 caused by down-regulating hnRNP G in ALS.

\section{Conclusions}

Our results showed that the expression of TDP-43 and Bax were significantly increased after downregulating the expression of hnRNP G in PC12 cells. It is suggested that the absence of hnRNP G might 
stimulate the increase of TDP-43 transcription, or destroy the automatic regulation of TDP-43 mRNA and slow down the degradation of TDP-43 protein. At the onset stage of TG mice, the content of hnRNP G protein significantly decreased, which might further aggravate the abnormal accumulation of TDP-43 and lead to the damage of neural cells.

\section{Abbreviations}

hnRNP G Heterologous ribonucleoprotein G

ALS Amyotrophic lateral sclerosis

PC 12 Pheochromocytoma 12 cells

CCK8 Cell counting kit 8

TDP43 TAR DNA-binding protein 43

Bax BCL2-associated X protein

SOD1 Superoxide dismutase 1

FUS Fused in sarcoma/translocated in liposarcoma

OPTN Optineurin

Ubqln2 Ubiquilin 2

NEFH Neurofilament, heavy polypeptide

\section{Declarations}

\section{Ethical Approval and Consent to participate}

Animals were handled in accordance with the Guide for the Care and Use of Laboratory Animals published by the US National Institutes of Health $[(\mathrm{NIH})$ publication no. 85-23, revised 1996). All the animal experiments and maintenance were approved by the Laboratory Animal Ethics Committee of Jiangxi Provincial People's Hospital, First Affiliated Hospital of Nanchang Medical College, Affiliated People's Hospital of Nanchang University (ACUC Number 2019-11-02).

\section{Consent for publication}

All authors have read the manuscript and indicated consent for publication.

\section{Availability of supporting data}


The data generated during this study is included in this published article and its additional files.

\section{Competing interests}

The authors declare that they have no competing interests.

\section{Funding}

This work was funded by a grant from the Committee of National Natural Science Foundation of China (30560042, 81160161 and 81360198), Education Department of Jiangxi Province (GJJ13198, GJJ170021), Jiangxi provincial department of science and technology ([2014]-47, 20142BBG70062, 20171BAB215022, 20192BAB205043), and Health Commission of Jiangxi province (20181019). All other authors have no competing interests.

\section{Authors' contributions}

$\mathrm{FY}$ and RX designed the study, analyzed the data, performed western blots, immunohistochemistry, cell culture experiment and wrote the manuscript. FY, XL, WC, YZ, PH and SJ performed the statistical analysis and animal dissection for isolating spinal cord. $\mathrm{FY}, \mathrm{XL}$ and $\mathrm{WC}$ generated the $\mathrm{TG}\left(\mathrm{SOD} 1{ }^{*} \mathrm{G} 93 \mathrm{~A}\right) 1 \mathrm{Gur}$ transgenic mice. Further, $\mathrm{FY}, \mathrm{XL}$ and WC did character isolation and validation of the transgenic mice model and wrote the manuscript. All authors read and approved the final manuscript.

\section{Acknowledgements}

Not applicable.

\section{Authors' information}

Department of Neurology, Jiangxi Provincial People's Hospital, First Affiliated Hospital of Nanchang Medical College, Affiliated People's Hospital of Nanchang University, Nanchang 330006, Jiangxi, China

*Correspondence: Renshi Xu, Email: xurenshi@ncu.edu.cn

${ }^{\#}$ Contributed equally.

\section{References}

1. Taylor JP, Brown RH, Cleveland DW. Decoding ALS: from genes to mechanism. Nature. 2016;539:197-206.

2. Van Damme P, Robberecht W. Van Den Bosch L. Modelling amyotrophic lateral sclerosis: progress and possibilities. Dis Model Mech. 2017;10:537-49.

3. Al-Chalabi A, Jones A, Troakes C, King A, Al-Sarraj S. The genetics and neuropathology of amyotrophic lateral sclerosis. Acta Neuropathol. 2012;124:339-52., van den Berg LH. 
4. Robberecht W, Philips T. The changing scene of amyotrophic lateral sclerosis. Nat Rev Neurosci. 2013;14:248-64.

5. Shibata N, Hirano A, Kobayashi M, Siddique T, Deng HX, Hung WY. et al. Intense superoxide dismutase-1 immunoreactivity in intracytoplasmic hyaline inclusions of familial amyotrophic lateral sclerosis with posterior column involvement. J Neuropathol Exp Neurol. 1996;55:481-90.

6. Mackenzie IRA, Bigio EH, Ince PG, Geser F, Neumann M, Cairns NJ. et al. Pathological TDP-43 distinguishes sporadic amyotrophic lateral sclerosis from amyotrophic lateral sclerosis with SOD1 mutations. Ann Neurol. 2007;61:427-34.

7. Deng H-X, Zhai H, Bigio EH, Yan J, Fecto F, Ajroud K. et al. FUS-immunoreactive inclusions are a common feature in sporadic and non-SOD1 familial amyotrophic lateral sclerosis. Ann Neurol. 2010;67:739-48.

8. Rosen DR, Siddique T, Patterson D, Figlewicz DA, Sapp P, Hentati A. et al. Mutations in Cu/Zn superoxide dismutase gene are associated with familial amyotrophic lateral sclerosis. Nature. 1993;362:59-62.

9. Maruyama H, Morino H, Kawakami H. [Causative Genes for Amyotrophic Lateral Sclerosis]. Brain Nerve. 2016;68:1081-6.

10. Gamez J, Corbera-Bellalta M, Nogales G, Raguer N, García-Arumí E, Badia-Canto M. et al. Mutational analysis of the $\mathrm{Cu} / \mathrm{Zn}$ superoxide dismutase gene in a Catalan ALS population: should all sporadic ALS cases also be screened for SOD1? J Neurol Sci. 2006;247:21-8.

11. Cooper-Knock J, Hewitt C, Highley JR, Brockington A, Milano A, Man S. et al. Clinico-pathological features in amyotrophic lateral sclerosis with expansions in C9ORF72. Brain. 2012;135:751-64.

12. Neumann M, Sampathu DM, Kwong LK, Truax AC, Micsenyi MC, Chou TT. et al. Ubiquitinated TDP-43 in frontotemporal lobar degeneration and amyotrophic lateral sclerosis. Science. 2006;314:130-3.

13. Thomas $M$, Alegre-Abarrategui $J$, Wade-Martins R. RNA dysfunction and aggrephagy at the centre of an amyotrophic lateral sclerosis/frontotemporal dementia disease continuum. Brain. 2013;136:1345-60.

14. Chen S, Sayana P, Zhang X, Le W. Genetics of amyotrophic lateral sclerosis: an update. Mol Neurodegener. 2013;8:28.

15. Renton AE, Chiò A, Traynor BJ. State of play in amyotrophic lateral sclerosis genetics. Nat Neurosci. 2014;17:17-23.

16. MacNair L, Xiao S, Miletic D, Ghani M, Julien J-P, Keith J. et al. MTHFSD and DDX58 are novel RNAbinding proteins abnormally regulated in amyotrophic lateral sclerosis. Brain. 2016;139:86-100.

17. Bakkar N, Kovalik T, Lorenzini I, Spangler S, Lacoste A, Sponaugle K. et al. Artificial intelligence in neurodegenerative disease research: use of IBM Watson to identify additional RNA-binding proteins altered in amyotrophic lateral sclerosis. Acta Neuropathol. 2018;135:227-47.

18. Lagier-Tourenne $C$, Polymenidou M, Cleveland DW. TDP-43 and FUS/TLS: emerging roles in RNA processing and neurodegeneration. Hum Mol Genet. 2010;19:R46-64. 
19. D'Ambrogio A, Buratti E, Stuani C, Guarnaccia C, Romano M, Ayala YM. et al. Functional mapping of the interaction between TDP-43 and hnRNP A2 in vivo. Nucleic Acids Res. 2009;37:4116-26.

20. Hoell JI, Larsson E, Runge S, Nusbaum JD, Duggimpudi S, Farazi TA. et al. RNA targets of wild-type and mutant FET family proteins. Nat Struct Mol Biol. 2011;18:1428-31.

21. Gass J, Lee WC, Cook C, Finch N, Stetler C, Jansen-West K. et al. Progranulin regulates neuronal outgrowth independent of sortilin. Mol Neurodegener. 2012;7:33.

22. Lagier-Tourenne C, Polymenidou M, Hutt KR, Vu AQ, Baughn M, Huelga SC. et al. Divergent roles of ALS-linked proteins FUS/TLS and TDP-43 intersect in processing long pre-mRNAs. Nat Neurosci. 2012;15:1488-97.

23. Kwon I, Xiang S, Kato M, Wu L, Theodoropoulos P, Wang T. et al. Poly-dipeptides encoded by the C9orf72 repeats bind nucleoli, impede RNA biogenesis, and kill cells. Science. 2014;345:1139-45.

24. Wen X, Tan W, Westergard T, Krishnamurthy K, Markandaiah SS, Shi Y. et al. Antisense prolinearginine RAN dipeptides linked to C9ORF72-ALS/FTD form toxic nuclear aggregates that initiate in vitro and in vivo neuronal death. Neuron. 2014;84:1213-25.

25. Farg MA, Konopka A, Soo KY, Ito D, Atkin JD. The DNA damage response (DDR) is induced by the C9orf72 repeat expansion in amyotrophic lateral sclerosis. Hum Mol Genet. 2017;26:2882-96.

26. Walker C, Herranz-Martin S, Karyka E, Liao C, Lewis K, Elsayed W. et al. C9orf72 expansion disrupts ATM-mediated chromosomal break repair. Nat Neurosci. 2017;20:1225-35.

27. Zhang J, Liang H, Zhu L, Gan W, Tang C, Li J. et al. Expression and Distribution of Arylsulfatase B are Closely Associated with Neuron Death in SOD1 G93A Transgenic Mice. Mol Neurobiol. 2018;55:1323-37.

28. Jean-Philippe J, Paz S, Caputi M. hnRNP A1: the Swiss army knife of gene expression. Int J Mol Sci. 2013;14:18999-9024.

29. Honda H, Hamasaki H, Wakamiya T, Koyama S, Suzuki SO, Fujii N. et al. Loss of hnRNPA1 in ALS spinal cord motor neurons with TDP-43-positive inclusions. Neuropathology. 2015;35:37-43.

30. Suzuki H, Matsuoka M. hnRNPA1 autoregulates its own mRNA expression to remain non-cytotoxic. Mol Cell Biochem. 2017;427:123-31.

31. Sreedharan J, Blair IP, Tripathi VB, Hu X, Vance C, Rogelj B. et al. TDP-43 mutations in familial and sporadic amyotrophic lateral sclerosis. Science. 2008;319:1668-72.

32. Vance C, Rogelj B, Hortobágyi T. De Vos KJ, Nishimura AL, Sreedharan J, et al. Mutations in FUS, an RNA processing protein, cause familial amyotrophic lateral sclerosis type 6. Science. 2009;323:1208-11.

33. Kim HJ, Kim NC, Wang Y-D, Scarborough EA, Moore J, Diaz Z. et al. Mutations in prion-like domains in hnRNPA2B1 and hnRNPA1 cause multisystem proteinopathy and ALS. Nature. 2013;495:467-73.

34. Dreyfuss G, Matunis MJ, Piñol-Roma S, Burd CG. hnRNP proteins and the biogenesis of mRNA. Annu Rev Biochem. 1993;62:289-321. 
35. Geuens T, Bouhy D, Timmerman V. The hnRNP family: insights into their role in health and disease. Hum Genet. 2016;135:851-67.

36. Soulard M, Della Valle V, Siomi MC, Piñol-Roma S, Codogno P, Bauvy C. et al. hnRNP G: sequence and characterization of a glycosylated RNA-binding protein. Nucleic Acids Res. 1993;21:4210-7.

37. Elliott DJ, Venables JP, Newton CS, Lawson D, Boyle S, Eperon IC. et al. An evolutionarily conserved germ cell-specific hnRNP is encoded by a retrotransposed gene. Hum Mol Genet. 2000;9:2117-24.

38. Liu Y, Bourgeois CF, Pang S, Kudla M, Dreumont N, Kister L. et al. The germ cell nuclear proteins hnRNP G-T and RBMY activate a testis-specific exon. PLoS Genet. 2009;5:e1000707.

39. Kanhoush R, Beenders B, Perrin C, Moreau J, Bellini M, Penrad-Mobayed M. Novel domains in the hnRNP G/RBMX protein with distinct roles in RNA binding and targeting nascent transcripts. Nucleus. 2010;1:109-22.

40. Hofmann Y, Wirth B. hnRNP-G promotes exon 7 inclusion of survival motor neuron (SMN) via direct interaction with Htra2-beta1. Hum Mol Genet. 2002;11:2037-49.

41. Wang J, Gao Q-S, Wang Y, Lafyatis R, Stamm S, Andreadis A. Tau exon 10, whose missplicing causes frontotemporal dementia, is regulated by an intricate interplay of cis elements and trans factors. $J$ Neurochem. 2004;88:1078-90.

42. Pišlar AH, Zidar N, Kikelj D, Kos J. Cathepsin X promotes 6-hydroxydopamine-induced apoptosis of PC12 and SH-SY5Y cells. Neuropharmacology. 2014;82:121-31.

43. Dai M, Liu Y, Nie X, Zhang J, Wang Y, Ben J. et al. Expression of RBMX in the light-induced damage of rat retina in vivo. Cell Mol Neurobiol. 2015;35:463-71.

44. Zhang J, Li D, Shen A, Mao H, Jin H, Huang W. et al. Expression of RBMX after spinal cord injury in rats. J Mol Neurosci. 2013;49:417-29.

45. Tsend-Ayush E, O'Sullivan LA, Grützner FS, Onnebo SMN, Lewis RS, Delbridge ML. et al. RBMX gene is essential for brain development in zebrafish. Dev Dyn. 2005;234:682-8.

46. Graves JM, Gécz J, Hameister H. Evolution of the human X-a smart and sexy chromosome that controls speciation and development. Cytogenet Genome Res. 2002;99:141-5.

47. Liu C, Shi Z, Fan L, Zhang C, Wang K, Wang B. Resveratrol improves neuron protection and functional recovery in rat model of spinal cord injury. Brain Res. 2011;1374:100-9.

48. Rong W, Wang J, Liu X, Jiang L, Wei F, Hu X. et al. Naringin treatment improves functional recovery by increasing BDNF and VEGF expression, inhibiting neuronal apoptosis after spinal cord injury. Neurochem Res. 2012;37:1615-23.

49. Ayala YM. De Conti L, Avendaño-Vázquez SE, Dhir A, Romano M, D’Ambrogio A, et al. TDP-43 regulates its mRNA levels through a negative feedback loop. EMBO J 2011;30:277-88.

50. Koyama A, Sugai A, Kato T, Ishihara T, Shiga A, Toyoshima Y. et al. Increased cytoplasmic TARDBP mRNA in affected spinal motor neurons in ALS caused by abnormal autoregulation of TDP-43. Nucleic Acids Res. 2016;44:5820-36. 
51. Deshaies J-E, Shkreta L, Moszczynski AJ, Sidibé H, Semmler S, Fouillen A. et al. TDP-43 regulates the alternative splicing of hnRNP A1 to yield an aggregation-prone variant in amyotrophic lateral sclerosis. Brain. 2018;141:1320-33.

52. Suzuki H, Shibagaki Y, Hattori S, Matsuoka M. Nuclear TDP-43 causes neuronal toxicity by escaping from the inhibitory regulation by hnRNPs. Hum Mol Genet. 2015;24:1513-27.

\section{Figures}




\section{Figure 1}

\section{A Anterior horn}
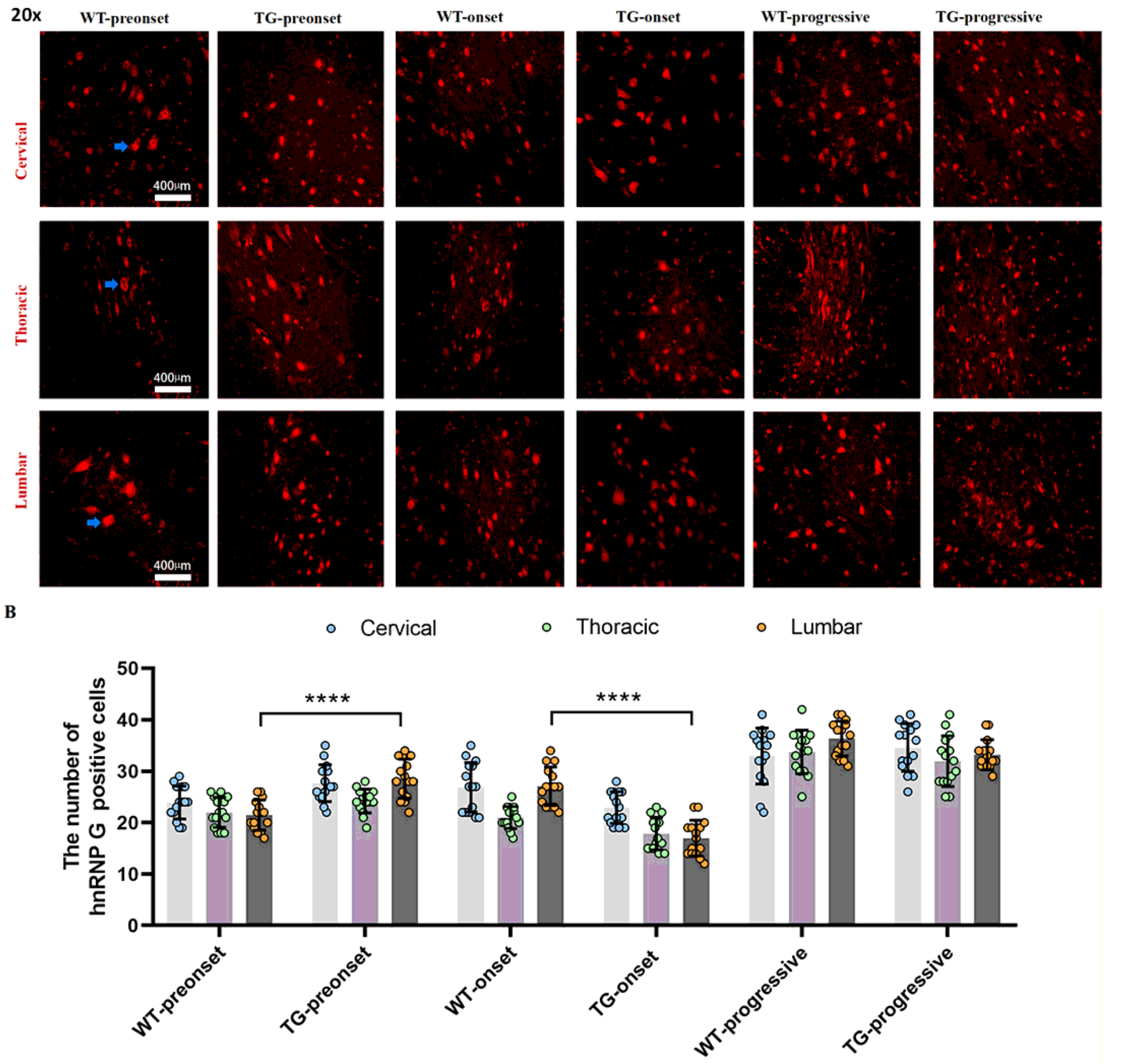

The different segments of spinal cord,periods of WT mice and stages of TG(SOD1*G93A)Gur mice

\section{Figure 1}

The distribution of hnRNP G in the anterior horn of spinal cord of mice at the different stages. a The representative images of hnRNP G positive cells distribution in the anterior horn of spinal different segments of mice at different stages. b The statistical analysis of hnRNP $G$ positive cells number in the anterior horn of spinal different segments of mice at different stages. The distribution of hnRNP G positive cells in the spinal lumbar segment of TG mice at the pre-onset stage was significantly higher 
than that of control group (WT mice) ( $* \star \star * P<0.0001, n=5$ per group), but it was significantly lower than that of control group at the onset stage ( $* \star \star x<0.0001, n=5$ per group). The arrow points to hnRNP $G$ positive cells. There were 3 technical replicates performed.

\section{Figure 2}

A Central canal and its around gray

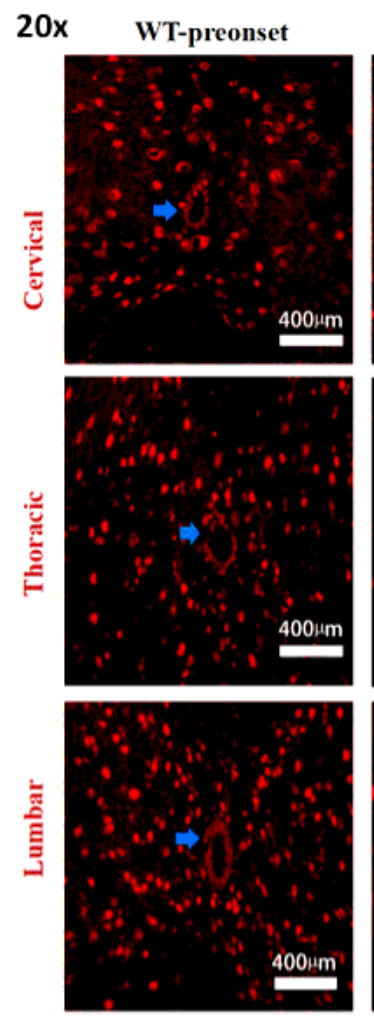

TG-preonset

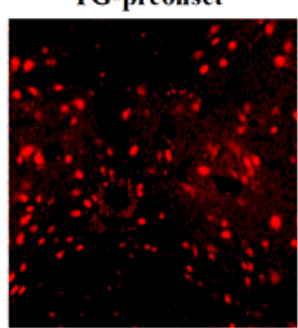

WT-onset

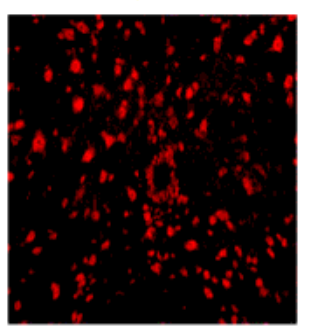

TG-onset

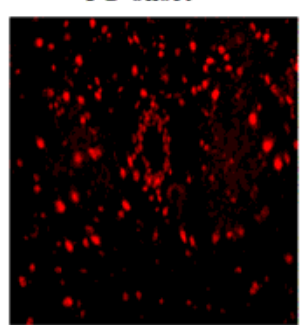

WT-progressive

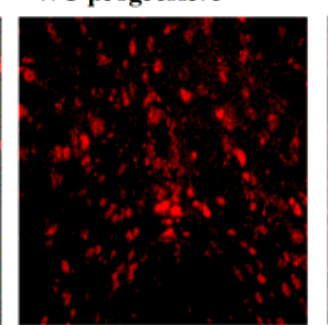

TG-progressive
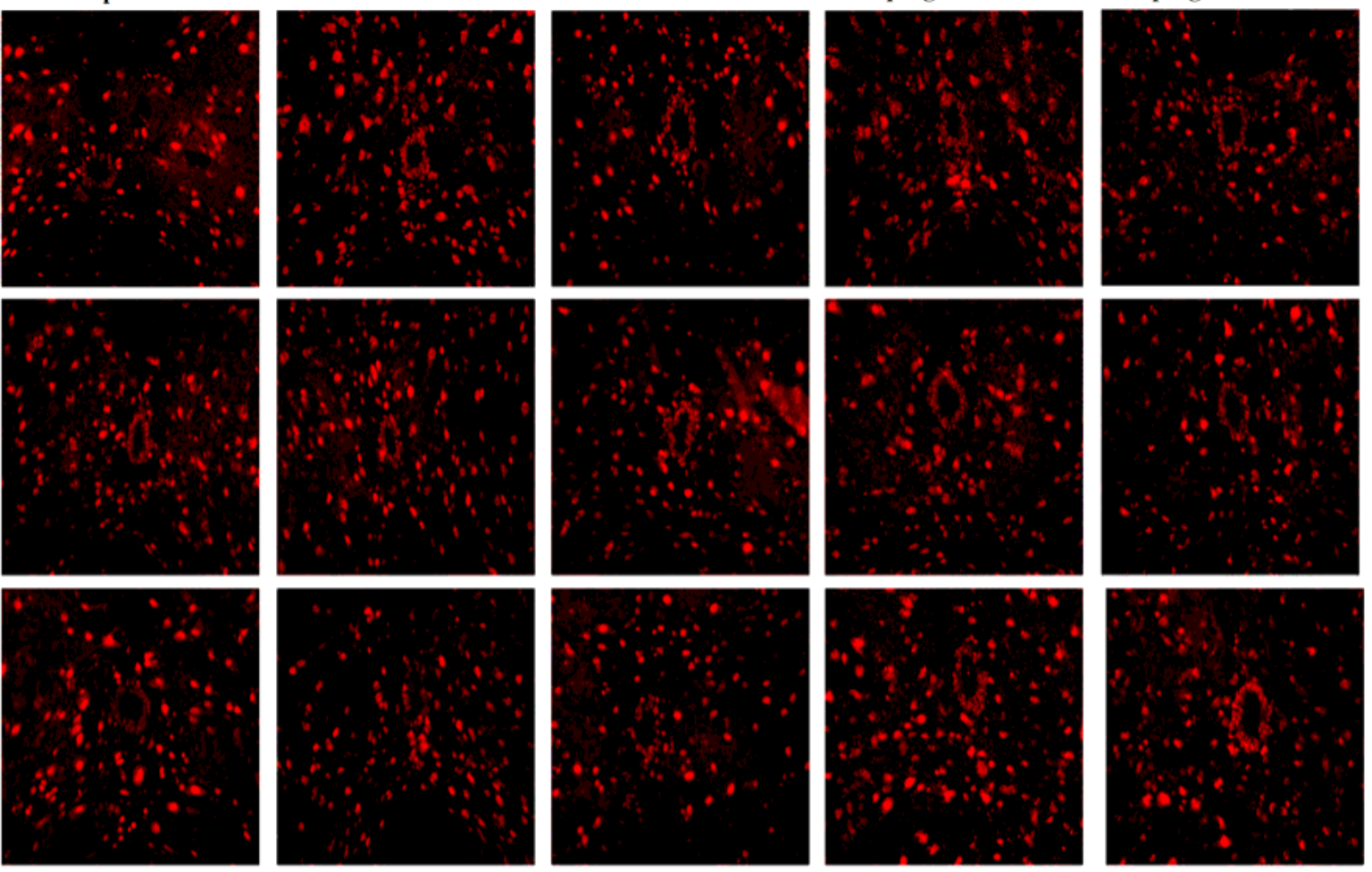

- Cervical

- Thoracic

- Lumbar

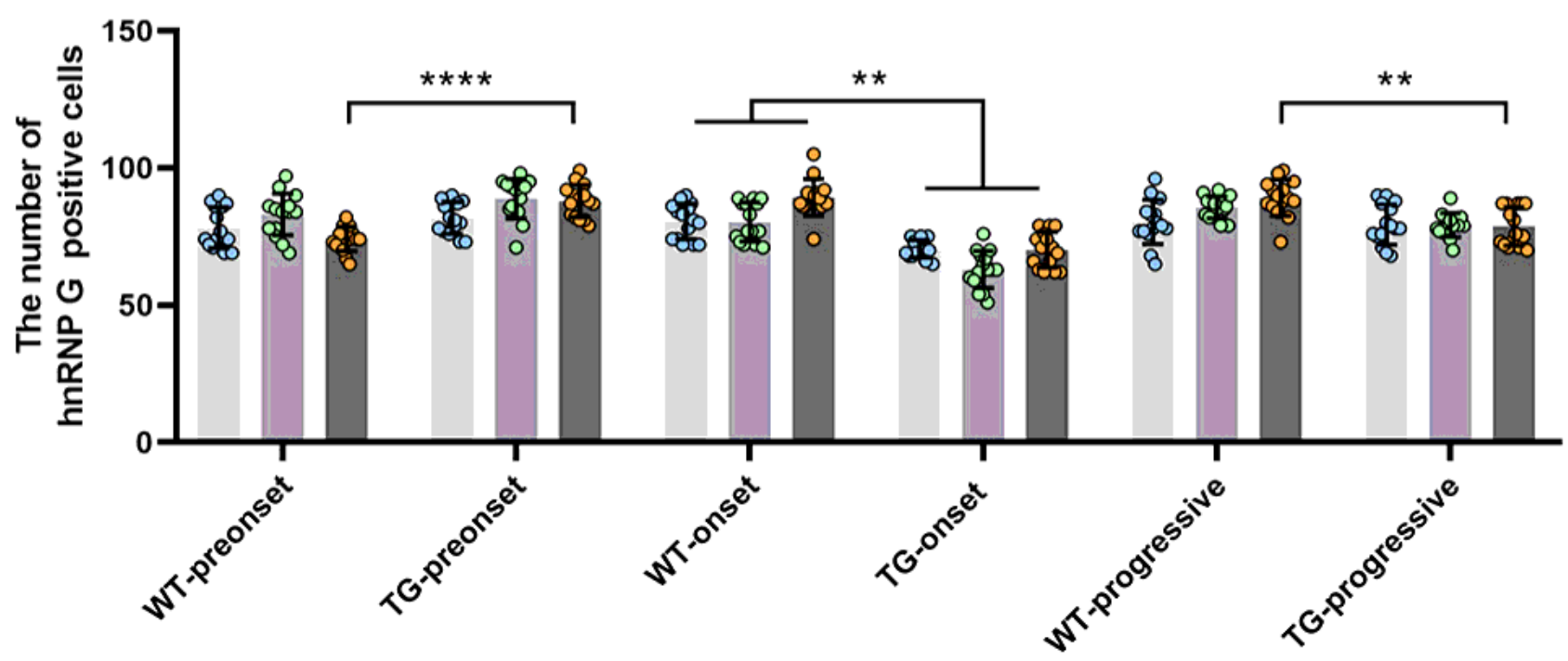

The different segments of spinal cord, periods of WT mice and stages of TG(SOD1*G93A)Gur mice

Figure 2

The distribution of hnRNP G in the central canal and its surrounding gray matter of spinal cord of mice at the different stages. a The representative images of hnRNP G positive cells distribution in the central 
canal and its surrounding gray matter of spinal different segments of mice at different stages. $b$ The statistical analysis of hnRNP G positive cells number in the central canal and its surrounding gray matter of spinal different segments of mice at different stages. The distribution of hnRNP G positive cells in the whole spinal cord of TG mice at the onset stage was significantly less than that in the control group $(\star \star \star \star P<0.0001, n=5$ per group). The distribution of hnRNP $G$ positive cells in the spinal lumbar segment of TG mice was significantly higher than that in the control group at the pre-onset stage ${ }^{\star \star *} P<0.01, n=5$ per group), and significantly lower than that in the control group at the progressive stage ( ${ }^{\star *} P<0.01, n=5$ per group). The arrow points to hnRNP G positive cells. There were 3 technical replicates performed. 


\section{Figure 3}

\section{A Posterior horn}
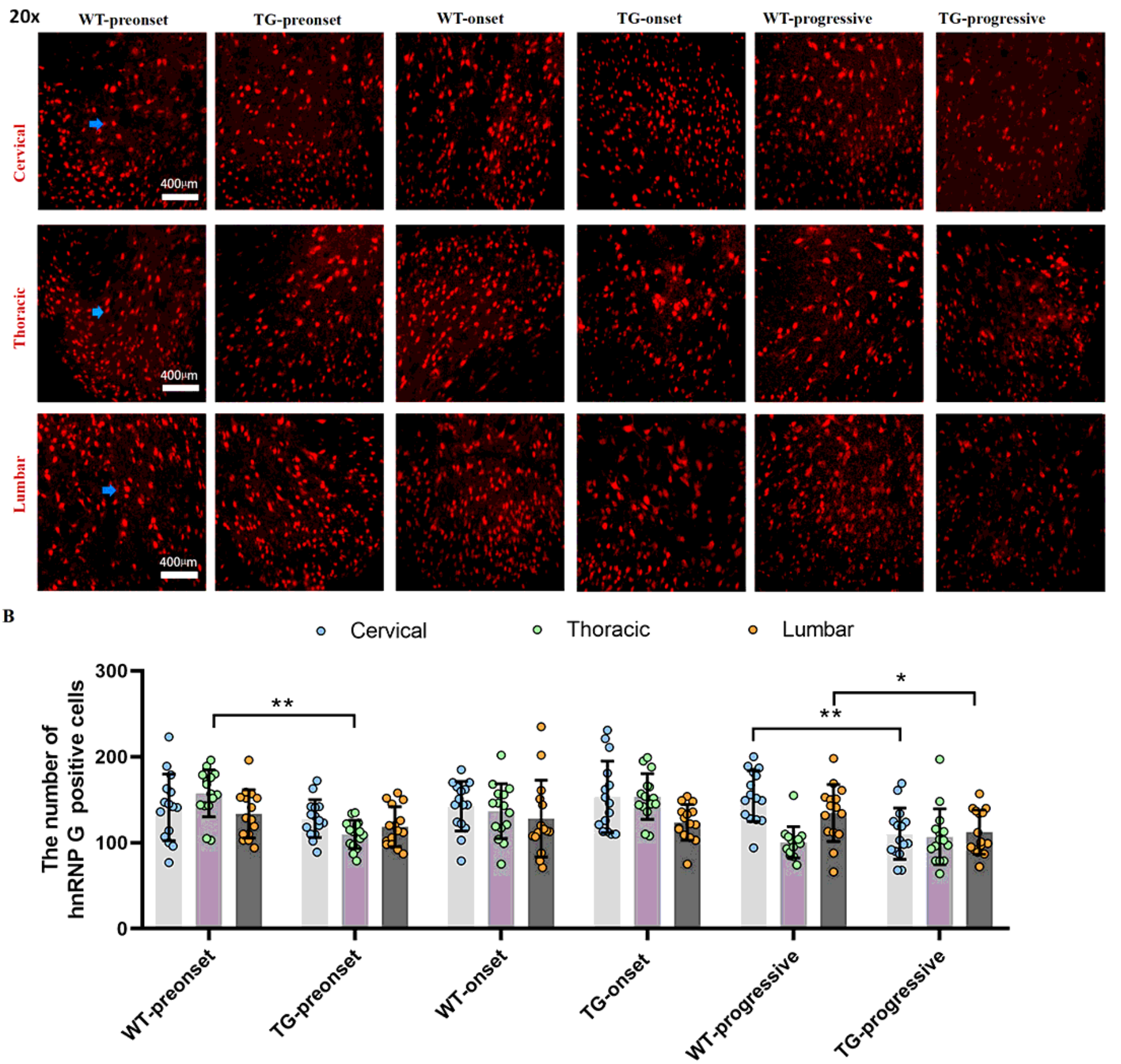

The different segments of spinal cord, periods of WT mice and stages of TG(SOD1*G93A)Gur mice

\section{Figure 3}

The distribution of hnRNP G in the posterior horn of spinal cord of mice at the different stages. a The representative images of hnRNP G positive cells distribution in the posterior horn of spinal different segments of mice at different stages. $b$ The statistical analysis of hnRNP $G$ positive cells number in the posterior horn of spinal different segments of mice at different stages. The distribution of hnRNP G positive cells in the spinal cervical and lumbar segments of TG mice at the progressive stage was 
significantly lower than that in the control group ( ${ }^{*} P<0.05, n=5$ per group). The arrow points to hnRNP $G$ positive cells. There were 3 technical replicates performed.

\section{Figure 4}

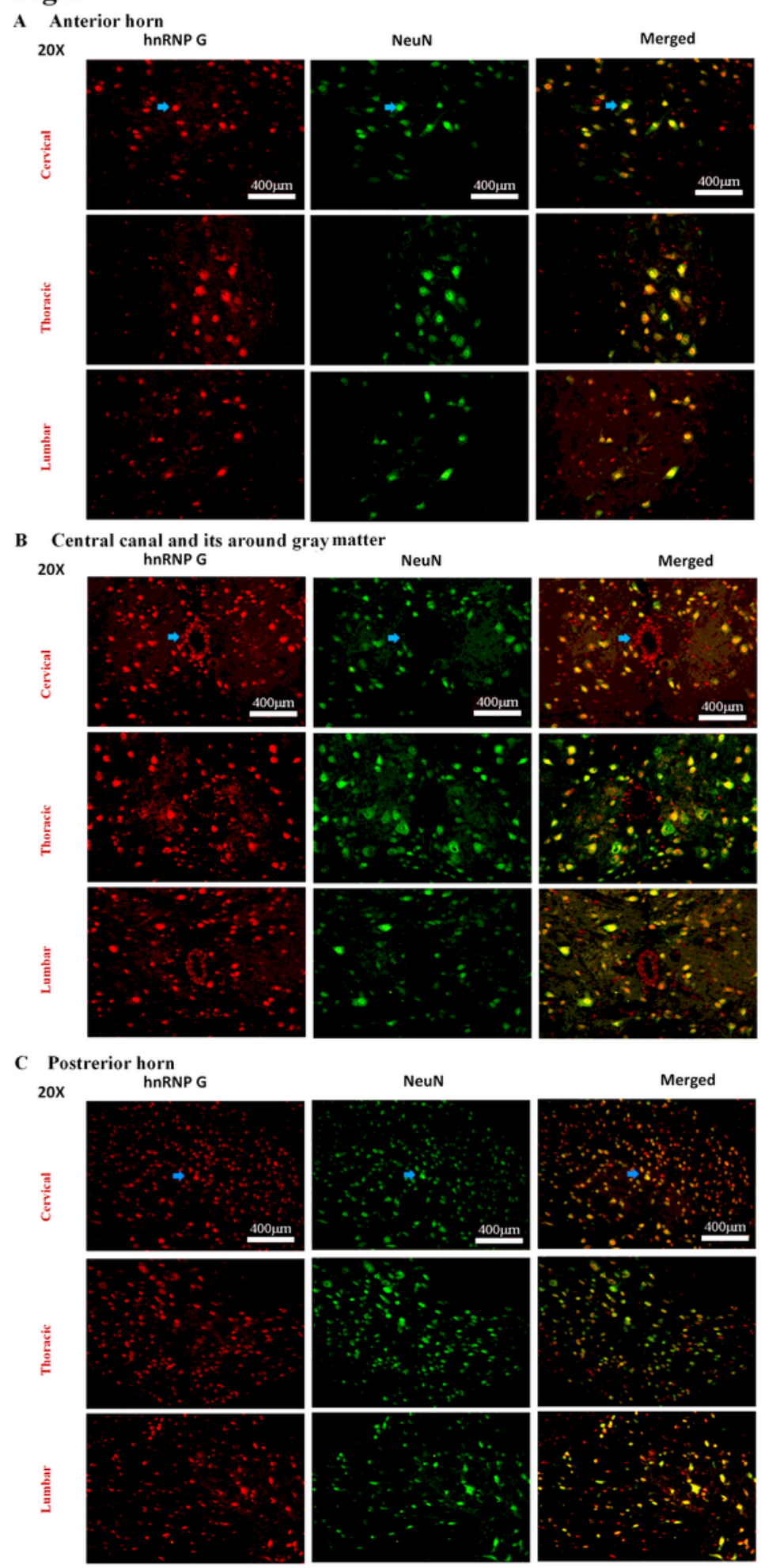

\section{Figure 4}

The double labeled immunofluorescent staining of hnRNP G and NeuN in the anterior horn, the central canal and its surrounding gray matter, and the posterior horn of different spinal cord segment of TG mice. The immunofluorescent double labeled representative images of hnRNP G and NeuN in the cervical 
segment a, the central canal and its surrounding gray matter (b) and the posterior horn (c) of spinal cord in TG mice. The neurons were doubly labeled by NeuN and hnRNP G, showed the immunocolocalization.

\section{Figure 5}
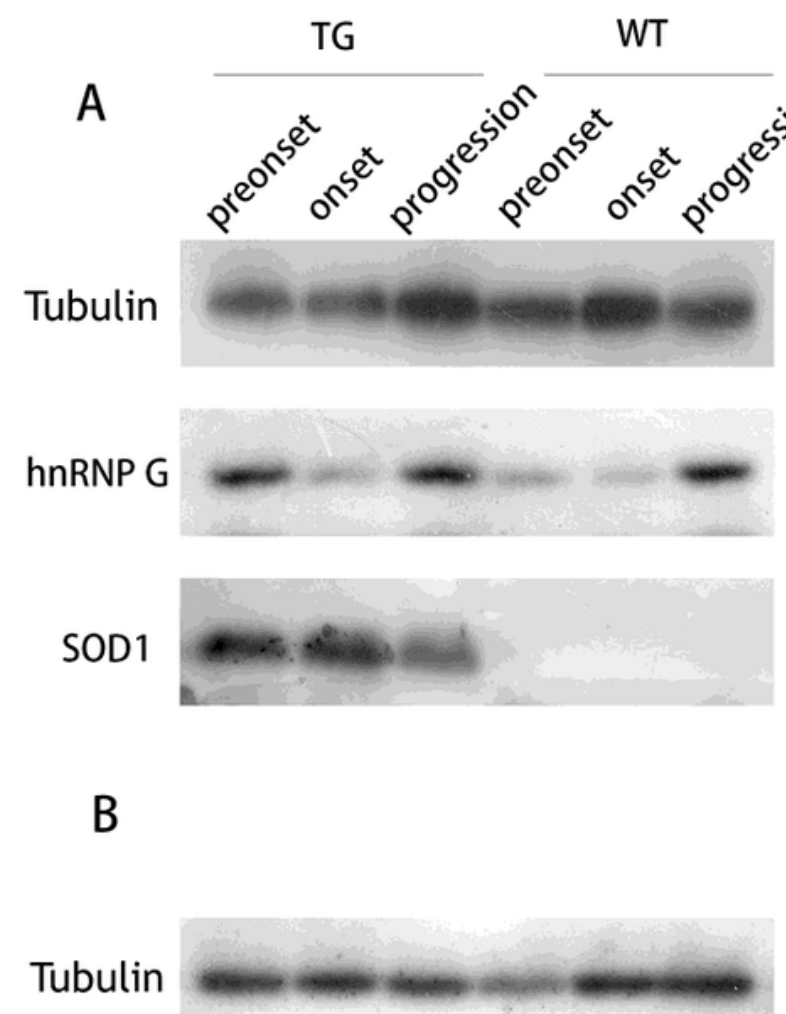

$52 \mathrm{KDa}$

$18 \mathrm{KDa}$

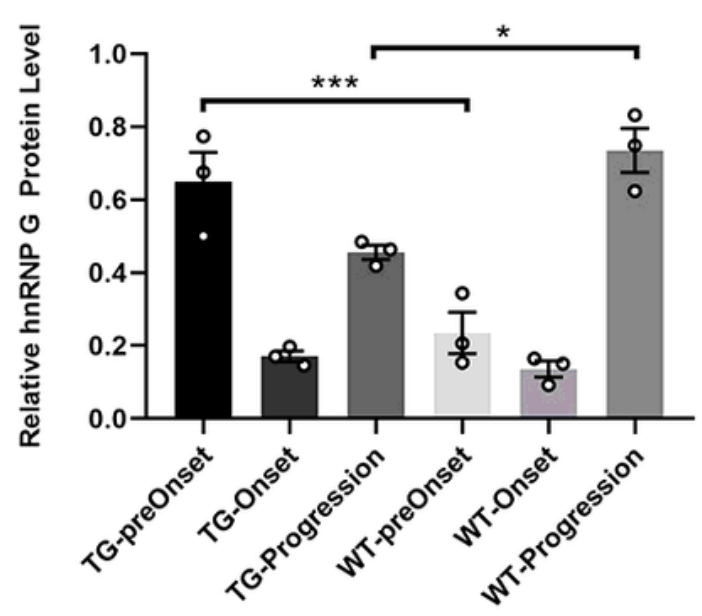

hnRNP G

$42 \mathrm{KDa}$

KDa

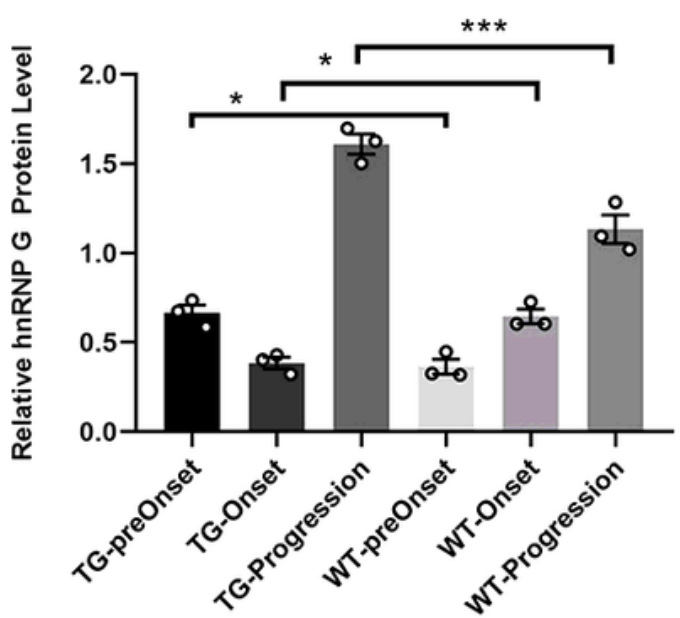

C

$42 \mathrm{KDa}$

Tubulin

$52 \mathrm{KDa}$

hnRNP G

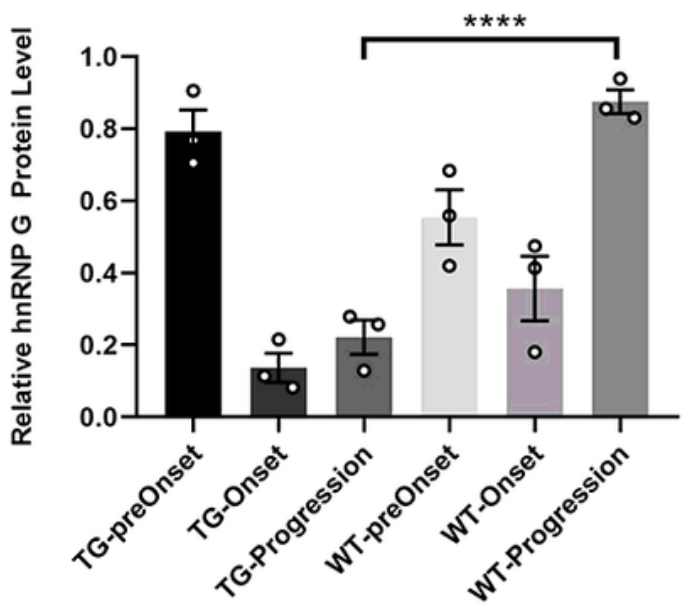

Figure 5

The semi-quantitative analysis of hnRNP G protein in different spinal cord segments of mice. The Western blot of hnRNP G protein in the different segments of spinal cord of mice at different stages. a The expression of hnRNP G protein in the cervical segment of spinal cord in TG mice was significantly 
higher than that in the control group at the pre-onset stage ( $\left.{ }^{\star \star P} \mathrm{P}<0.01\right)$ and significantly lower at the progression stage ( ${ }^{*} \mathrm{P}<0.05, \mathrm{n}=3$ per group). $\mathrm{b}$ The expression of $\mathrm{hnRNP} G$ protein in the thoracic segment of spinal cord in TG mice significantly increased at the pre-onset stage $\left({ }^{\star} P<0.05\right)$, significantly decreased at the onset stage $\left({ }^{*} P<0.05\right)$, and significantly increased at the progression stage compared with the control group ( ${ }^{\star *} \mathrm{P}<0.001, \mathrm{n}=3$ per group). $\mathrm{c}$ The expression of hnRNP $\mathrm{G}$ protein in the lumbar segment of spinal cord of TG mice was significantly lower than that of control group at both onset $(* \star P<0.01)$ and progression stage ( ${ }^{* \star *} \mathrm{P}<0.001, \mathrm{n}=3$ per group).

\section{Figure 6}
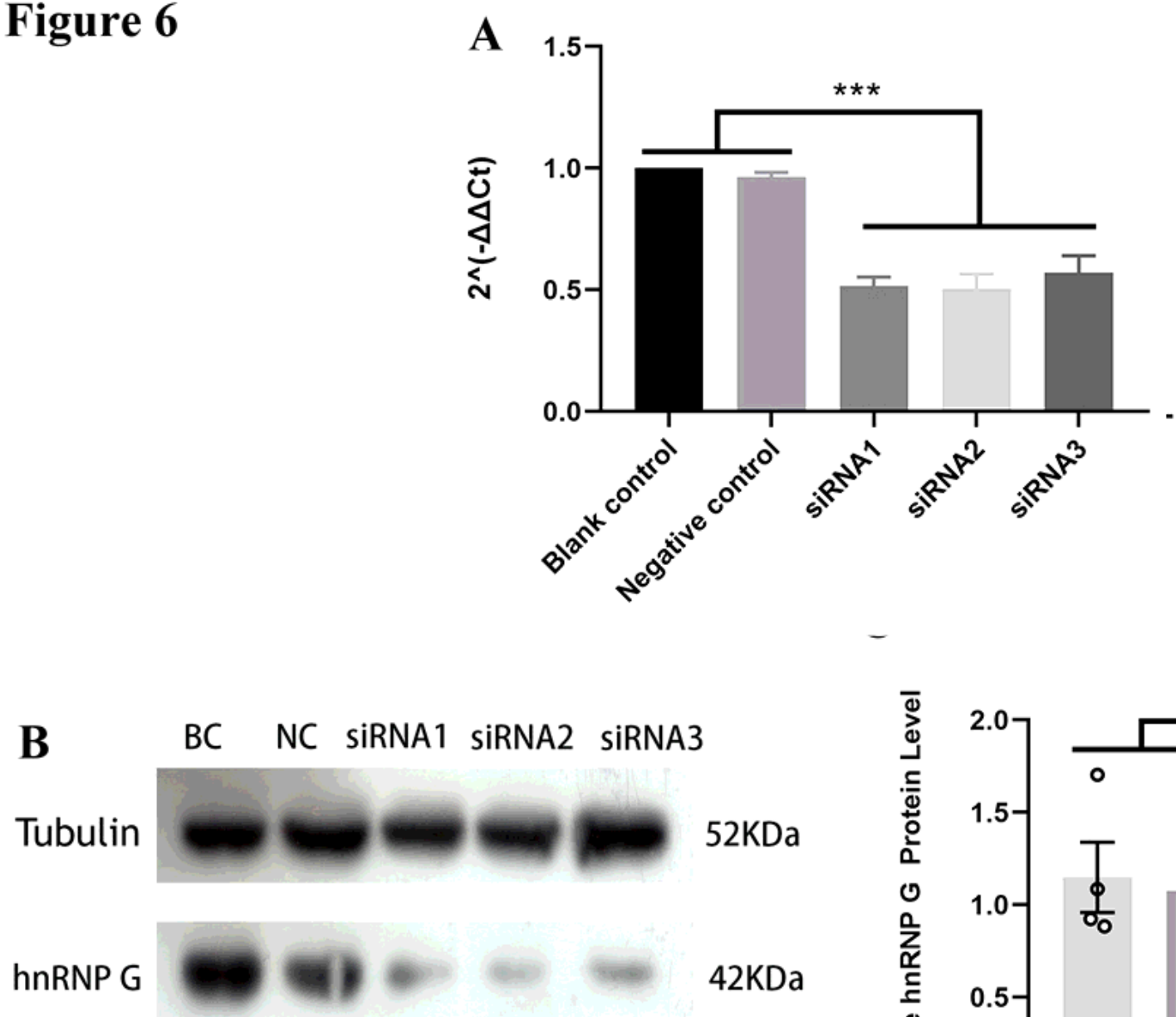

$52 \mathrm{KDa}$

$42 \mathrm{KDa}$

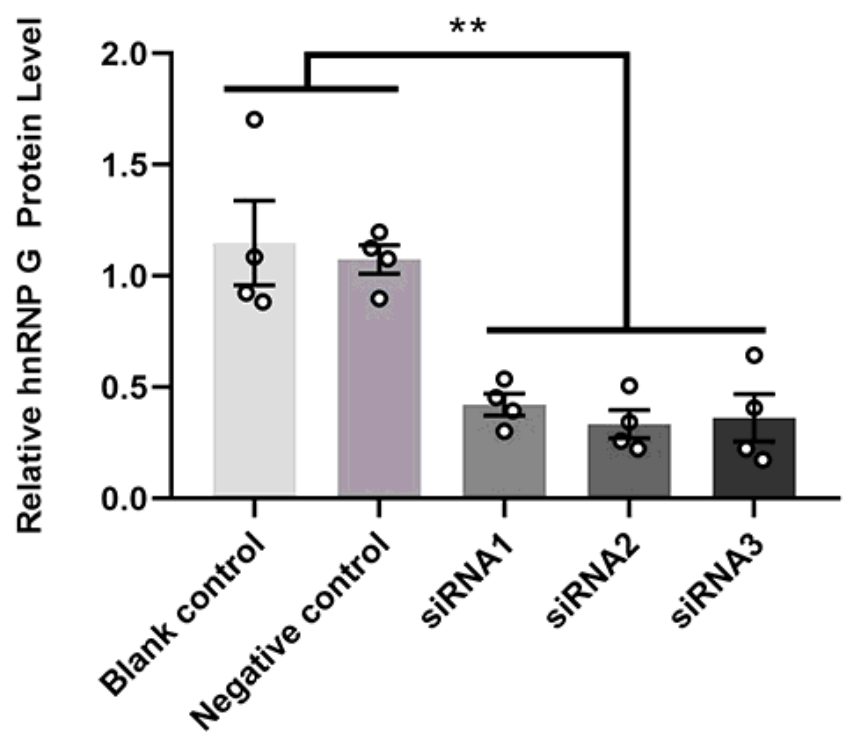

Figure 6

a The QRT PCR detection of hnRNP G mRNA expression in PC12 cells after the interference of hnRNP gsiRNA compared with control group. b The image of Western blot. c The semi-quantitative analysis of hnRNP G protein after hnRNP G gene silenced in PC12 cells by Western blot. After the interference of hnRNP G-siRNA in PC12 cells, the results of QRT PCR showed that the silenced efficiency of three siRNA sequences was significant ( $\left.{ }^{* *} \mathrm{P}<0.001\right)$. The expression of hnRNP G protein in the transfection group 
was significantly lower than that in the blank and negative control groups $\left({ }^{*} \mathrm{P}<0.001\right)$. There were at least 3 technical replicates performed.

\section{Figure 7}
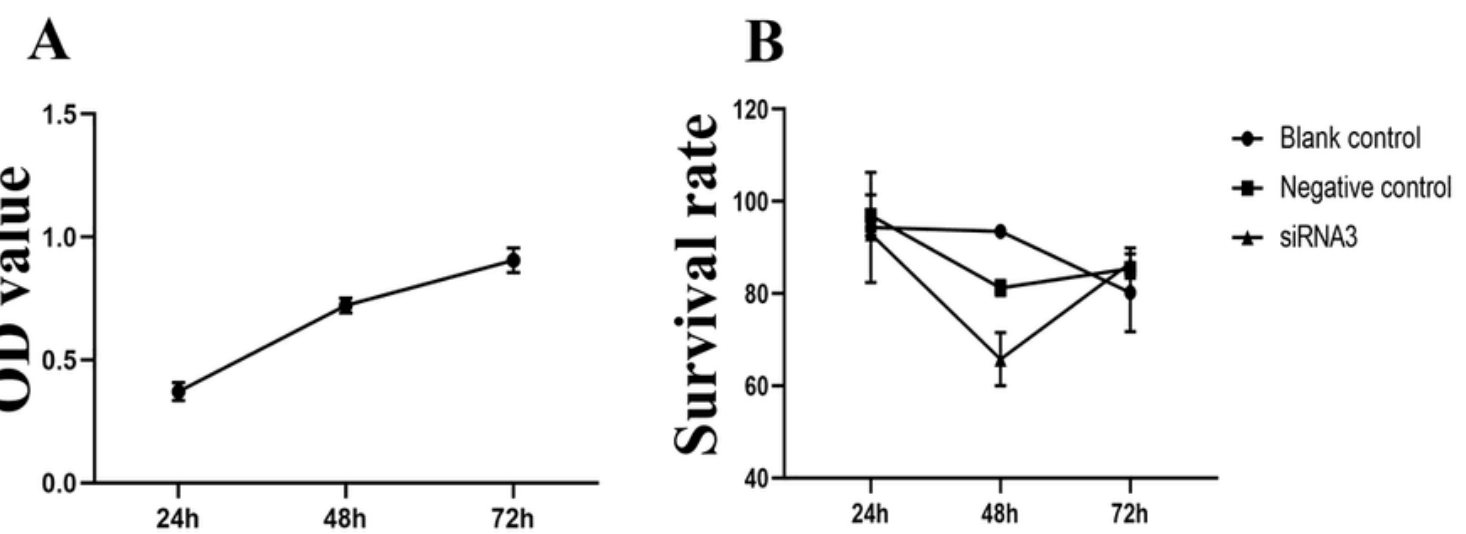

Normal growth curve of PC12 cells Growth curve of treatment PC12 cells
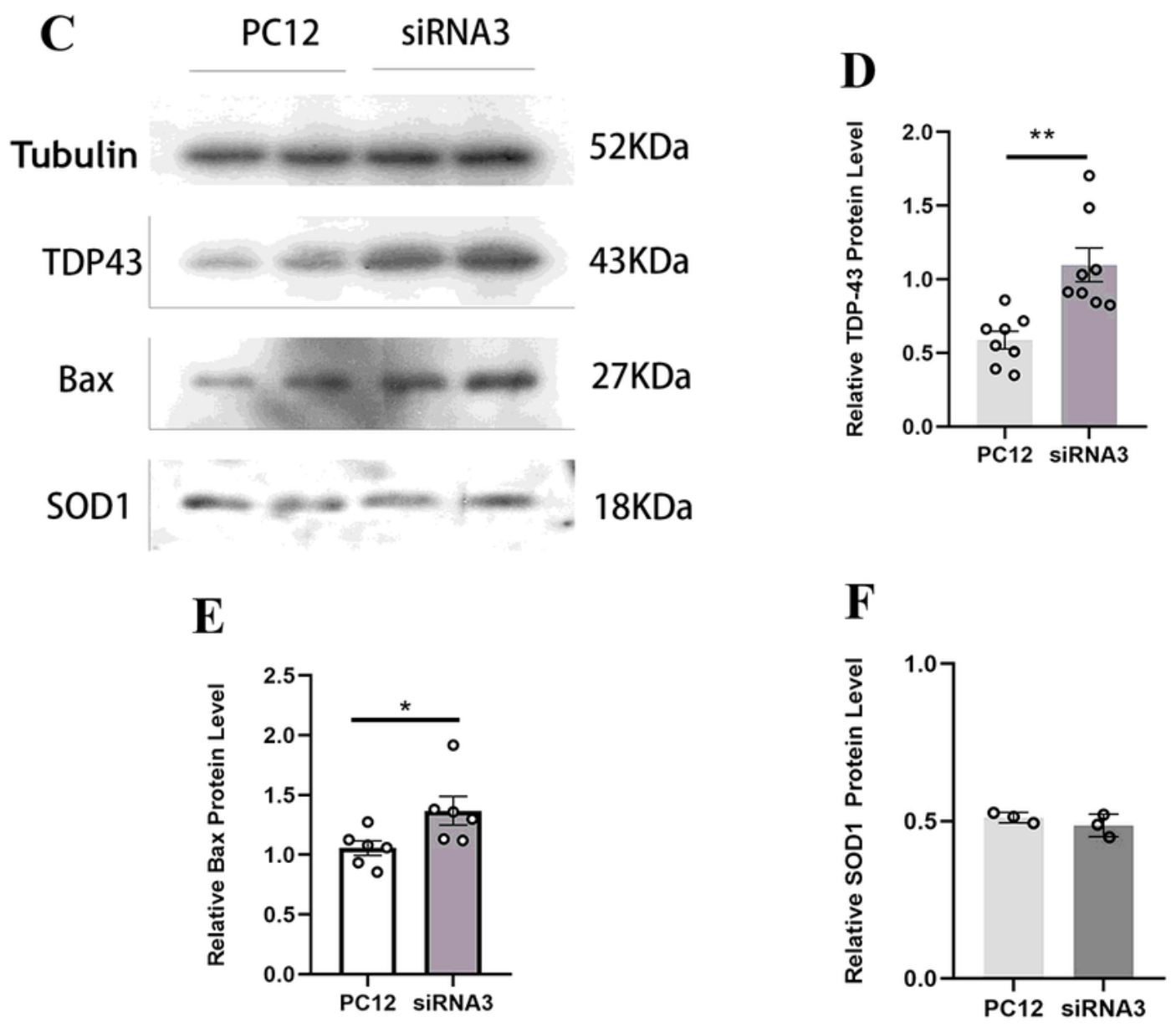

Figure 7

The cell growth curve before and after hnRNP G gene silenced, the Western blot semi-quantitative analysis of TDP-43, Bax, SOD1 expression in PC12 cells after hnRNP G-siRNA interfered. a The normal growth curve of PC12 cells. b The growth curve of PC12 cells after the interference of hnRNP G-siRNA. It 
showed that the survival rate of PC12 cells after the interference of hnRNP G-siRNA was lower than that of normal and negative control cells $\left({ }^{*} \mathrm{P}<0.01\right)$. $c$ After gene silenced, the expression of related proteins in PC12 cells was detected by Western blot. d TDP43 protein significantly increased compared with control group ( ${ }^{\star \star} \mathrm{P}<0.01$ ), e Bax protein also significantly increased compared with control group $\left({ }^{*} \mathrm{P}<0.05\right) . \mathrm{f}$ SOD1 protein did not significantly change compared with control group. There were at least 3 technical replicates performed.

\section{Supplementary Files}

This is a list of supplementary files associated with this preprint. Click to download.

- SupplementaryInformation.docx 